\title{
mRNA expression of glucocorticoid receptor and serological and virological markers of chronic hepatitis B
}

\author{
BING MEI $^{1}$, YONGLING CHEN ${ }^{1}$, WEIJIA LIU ${ }^{2}$, LINYUN LI $^{1}$ and CHANGFU WANG ${ }^{1}$ \\ Departments of ${ }^{1}$ Laboratory Medicine and ${ }^{2}$ Infectious Diseases, Jingzhou Hospital, Tongji Medical College, \\ Huazhong University of Science and Technology, Jingzhou, Hubei 434020, P.R. China
}

Received February 5, 2014; Accepted October 31, 2014

DOI: $10.3892 / \mathrm{mmr} .2014 .2931$

\begin{abstract}
Glucocorticoid receptor (GR) function is essential for glucocorticoid action on various effector cells. The aim of the present study was to investigate the mRNA expression profiles of GR $\alpha$ and GR $\beta$ in peripheral blood mononuclear cells (PBMC) and examine the association between the expression levels of the GR isoforms and the serological and virological hepatitis $B$ virus (HBV) status in patients with chronic hepatitis B (CHB). A total of 29 CHB patients were examined in the present study, which were divided into subgroups according to serological and virological markers. The levels of GR $\alpha$ and GR $\beta$ in PBMCs, HBV viral loads, HBV surface antigen (HBsAg), HBV e antigen (HBeAg) and pre-S1Ag were measured. A total of 43 healthy individuals served as controls. GR $\alpha$ was present in the PBMCs of all CHB patients and healthy controls, whereas GR $\beta$-specific products were present in only $93.1 \%$ of the CHB patients and $86.0 \%$ of the healthy controls. The GR $\alpha$ levels were positively correlated with the expression of GR $\beta$ in the CHB patients $(r=0.419 ; \mathrm{P}<0.05)$ and were significantly lower compared with those observed in the healthy controls $(60.51 \pm 23.73$, vs. $100.00 \pm 40.75 ; \mathrm{P}<0.001)$. Compared with the healthy controls, significant differences were observed in the mRNA expression of GR $\alpha$ in the CHB patients when stratified according to the HBeAg, pre-S1 Ag and HBV viral load status $(\mathrm{P}<0.05)$, but not in the pre-S1Ag-positive patients. These data demonstrated that the mRNA expression profile of GR $\alpha$ differed between the CHB patients and the healthy controls. In addition, the HBV serological and virological markers were not associated with the mRNA levels of the GR isoforms in the CHB patients.
\end{abstract}

Correspondence to: Professor Changfu Wang, Department of Laboratory Medicine, Jingzhou Hospital, Tongji Medical College, Huazhong University of Science and Technology, 1 Renming Road, Jingzhou, Hubei 434020, P.R. China

E-mail: jzzxyyjyk@hotmail.com

Key words: glucocorticoid receptor, chronic hepatitis B, serological marker, virological marker

\section{Introduction}

Hepatitis B virus (HBV) infection is one of the major causes of liver inflammation. Epidemiological data indicate that $\sim 15-20 \%$ of the population in Asia and the Western Pacific are affected by HBV (1). In susceptible individuals, primary HBV infection can be either symptomatic or asymptomatic and the majority of primary infections are self-limiting, with clearance of the virus and development of lasting immunity (2). However, an estimated 3-5\% of adults and up to $95 \%$ of children develop chronic HBV infection, which can also be either symptomatic or asymptomatic $(3,4)$. Therefore, it is not uncommon for hepatologists to encounter patients carrying an underlying, unnoticed hepatitis B infection requiring glucocorticoid treatment.

The reactivation of HBV is a common and well-recognized complication in patients with chronic HBV infection receiving cytotoxic or immunosuppressive therapy $(5,6)$. The risk of HBV reactivation is particularly high in areas where HBV is endemic, including Asia and the Western Pacific. Glucocorticoids, a component of the partial therapeutic procedure for chronic hepatitis B (CHB), are implicated as an important predisposing factor for HBV reactivation. In addition, long-term glucocorticoid treatment in patients with CHB increases the levels of hepatitis B virus surface antigen (HBsAg), hepatitis B virus core antigen and HBV DNA in hepatocytes (7). These observations of reactivation of latent infection and increasing levels of HBV markers during glucocorticoid therapy in CHB patients suggest that glucocorticoids affect HBV replication and gene expression in vivo.

The glucocorticoid receptor (GR) is essential for glucocorticoid action on various effector cells. In humans, alternative splicing of GR pre-mRNA generates two highly homologous isoforms, GR $\alpha$ and GR $\beta$ (8). GR $\alpha$ is a ligand-activated transcription factor, which regulates the expression of glucocorticoid-responsive genes by binding to a specific glucocorticoid-responsive element (GRE) DNA sequences. By contrast, GR $\beta$ is transcriptionally inactive, does not bind to glucocorticoid and may be an endogenous inhibitor of glucocorticoid action and an important negative regulator determining glucocorticoid sensitivity $(9,10)$. The stimulatory effect of glucocorticoids on the production of HBV markers is mediated through specific GRs (11). It has been demonstrated 
that GR $\alpha$ binds to a restriction fragment of the HBV genome containing the GRE consensus sequence and transmits a signal for augmenting the glucocorticoid-dependent activity of the HBV enhancer (12).

To the best of our knowledge, the mechanisms underlying the association between glucocorticoids and potentially fatal $\mathrm{HBV}$ reactivation remain to be fully elucidated, as do the expression profiles of the two GR isoforms in $\mathrm{CHB}$ patients. In the present study, the mRNA expression levels of GR $\alpha$ and $-\beta$ in peripheral blood mononuclear cells (PBMC) from $\mathrm{CHB}$ patients and healthy controls were examined. In addition, the correlation between the mRNA expression of the GR isoforms and HBV serological and virological characteristics in patients with $\mathrm{CHB}$ was examined.

\section{Materials and methods}

Study subjects. A total of 29 patients were recruited from the Department of Infectious Diseases at Jingzhou Hospital (Jingzhou, China). The diagnosis of CHB was based on the Guidelines for the Prevention and Treatment of CHB (13). No patients had evidence of decompensated liver disease or hepatocellular carcinoma and no markers for autoimmune liver disease, including antinuclear antibody, smooth muscle antibody and liver-kidney microsome type 1 autoantibody, were detected. All patients also tested negative for other viral infections, including hepatitis $\mathrm{A}$ virus, hepatitis $\mathrm{C}$ virus, hepatitis $\mathrm{E}$ virus, human immunodeficiency virus, cytomegalovirus and Epstein-Barr virus, had never received antiviral treatment or immunotherapy and had not received glucocorticoids for $>$ six months prior to blood collection. The control group consisted of 43 healthy individuals who were selected based on medical history evaluation and physical and laboratory examination from the Health Examination Center of the same hospital. The characteristics of the CHB patients and healthy controls are listed in Table I. All individuals provided written consent prior to their inclusion in the study and the study protocol was approved by the Medical Ethics Committee of Jingzhou Hospital.

Serological markers and HBV DNA assay. The levels of $\mathrm{HBsAg}$ and $\mathrm{HBeAg}$ were assessed through enzyme-linked immunoassays using diagnostic kits for hepatitis B virus surface antigen and e antigen, respectively (Wantai Biological Pharmacy Enterprise Co., Ltd., Beijing, China). Pre-S1Ag was also detected using a diagnostic kit for hepatitis B virus pre-S1 antigen (Alpha Biotechnology, Shanghai, China). The HBV DNA was extracted from $100 \mu 1$ patient serum using DNA extraction reagents in the diagnostic kit for hepatitis B virus DNA (Daan Gene, Guangzhou, China) according to the manufacturer's instructions. The viral load of the HBV DNA in the serum samples was then quantified through a high-sensitivity fluorescent quantitative polymerase chain reaction (qPCR) using a diagnostic kit for hepatitis B virus DNA (Daan Gene) and amplified using an ABI 7300 instrument (Applied Biosystems, Carlsbad, CA, USA). Each 50- $\mu$ l reaction contained $2 \mu 1$ sample extracts (template). Following initial heating at $93^{\circ} \mathrm{C}$ for $2 \mathrm{~min}$, the samples were subjected to 10 cycles of denaturation at $93^{\circ} \mathrm{C}$ for $45 \mathrm{sec}$ followed by annealing and synthesis for $1 \mathrm{~min}$ at $55^{\circ} \mathrm{C}$ and 30 cycles of denaturation at $93^{\circ} \mathrm{C}$ for $30 \mathrm{sec}$ followed by annealing and synthesis for $45 \mathrm{sec}$ at $55^{\circ} \mathrm{C}$.
Table I. Clinical, serological and virological markers in healthy controls and in CHB patients.

\begin{tabular}{lcc}
\hline Markers & Controls & CHB patients \\
\hline Number (n) & 43 & 29 \\
Gender (male/female) & $26 / 17$ & $18 / 11$ \\
Age (years) & $30(21-36)$ & $35(25-42)$ \\
ALT (IU/l) & $22.7(13-40)$ & $116.1(92-157)$ \\
HBV eAg (+/-) & $0 / 43$ & $13 / 16$ \\
HBV pre-S1Ag (+/-) & $0 / 43$ & $12 / 17$ \\
Viral load (log copies/ml) & NT & $6.48(4.04-8.73)$ \\
\hline
\end{tabular}

$\mathrm{CHB}$, chronic hepatitis B; ALT, alanine transaminase; HBV, hepatitis B virus; NT, not detected. For age, ALT and viral load, the median (range) for each group is shown.

Isolation of PBMCs. Blood ( $5 \mathrm{ml})$ was obtained by venipuncture into heparinized tubes. The PBMCs were isolated via density gradient centrifugation using Ficoll-Paque plus (Amersham Pharmacia Biotechnology, Uppsala, Sweden) according to the manufacturer's instructions. Cells were resuspended in $\mathrm{RBC}$ lysis buffer $\left(123 \mathrm{mmol} / \mathrm{NH}_{4} \mathrm{Cl}, 8 \mathrm{mmol} / 1 \mathrm{KHCO}_{3}\right.$, and $25 \mu \mathrm{mol} / 1$ EDTA) to lyse the remaining red blood cells, which were then collected by centrifugation at $300 \mathrm{x}$ g for $10 \mathrm{~min}$.

RNA isolation and reverse transcription (RT)-qPCR. All procedures for RNA isolation were performed immediately for all samples. The RNA extraction was performed using the RNAiso Plus kit (Takara Biotechnology, Tokyo, Japan) according to the manufacturer's instructions. A cell suspension of $5 \times 10^{6}$ PBMCs was dissolved in $2 \mathrm{ml}$ extraction reagent. The concentration of RNA was measured using a UV-1750 spectrophotometer (Shimadzu, Tokyo, Japan). All samples had a 260/280 absorbance ratio of 2 .0. The RNA integrity was determined by the presence of an 18S rRNA band when samples were analyzed by agarose gel electrophoresis running for 30 min with constant voltage $(100 \mathrm{~V})$ on Wide Mini-Sub ${ }^{\circledR}$ Cell GT electrophoresis system (Bio-Rad Laboratories, Segrate, Italy). Prior to RT, all RNA samples were treated with DNAse I (Invitrogen Life Technologies, Carlsbad, CA, USA) to remove any contaminating genomic DNA. cDNA was synthesized from 500 ng RNA and RT was performed using oligo-dT primers and an PrimeScript RT reagent kit (Takara Biotechnology, Dalian, China) according to the manufacturer's instructions. The RNA and cDNA samples were stored at $-80^{\circ} \mathrm{C}$ until use.

qPCR was performed for the GR $\alpha$ and GR $\beta$ splice variants using the common upstream primer: 5'-AAACTCTT GGATTCTATGCATGAA-3' and the specific downstream primers: GR $\alpha, 5^{\prime}$-TATTAATTCGACTTTCTTTAAGGCAA-3' and GR $\beta$, 5'-CCACGTATCCTAAAAGGGCAC-3', described by Boullu-Ciocca et al (14). Human GAPDH, which served as a normalization control to correct for loading discrepancies, was amplified from the same cDNA samples using the following primers: upstream primer, 5'-GAAGGTGAAGGTCGGAGTC-3' and downstream primer, 5'-GAAGATGGTGATGGGATTTC-3'. The Taq Man probes used were 5'-ATTCCCCGAGATGTTAGCTGAAATCA-3', 
5'-TCTTGGCGCTCAAAAAATAGAACTCA-3' and 5'-CAAGCTTCCCGTTCTCAGCC-3' for GR $\alpha$, GR $\beta$ and GAPDH, respectively. All primers and probes were synthesized by Takara Biotechnology (Dalian, China) The reaction contained $3 \mu \mathrm{l}$ cDNA template, $25 \mu 12 \mathrm{x}$ Premix $\mathrm{Ex}^{\mathrm{TM}} \mathrm{Taq}$ reagent, $1 \mu \mathrm{l}$ 50x 5-carboxy-X-rhodamine reference dye (ROX), $0.2 \mathrm{pmol} / \mu \mathrm{l}$ forward and reverse primer and $0.4 \mathrm{pmol} / \mu \mathrm{l}$ probe. Water was added to obtain a total volume of $50 \mu \mathrm{l}$. The reactions were performed using an ABI 7300 instrument (Applied Biosystems). The PCR cycling program consisted of a hot start activation step at $95^{\circ} \mathrm{C}$ for $30 \mathrm{sec}$ followed by 40 amplification cycles at $95^{\circ} \mathrm{C}$ for $5 \mathrm{sec}$ and $60^{\circ} \mathrm{C}$ for $31 \mathrm{sec}$. The relative quantification of target gene expression was evaluated using the comparative CT method, as previously described by Hettinger et al (15). The $\Delta \mathrm{CT}$ value was calculated by subtracting the target CT of each sample from its own GAPDH CT value. The $\Delta \Delta C T$ values were determined by using the highest sample $\Delta \mathrm{CT}$ value as an arbitrary constant to subtract from the $\Delta \mathrm{CT}$ values of all other samples. Fold-changes in the target gene expression were equivalent to $2^{-\Delta \Delta C T}$.

Statistical analysis. The results are expressed as the mean \pm standard deviation. All data were tested for a normal distribution using the Kolmogorov-Smirnov test. Statistical analysis of the data was evaluated using the one-way analysis of variance (ANOVA) or Student's t-test, as appropriate. In cases where the data was not normally distributed, a Mann-Whitney U test or a Kruskal-Wallis ANOVA with Dunn's method was used. The degree of association between the variables was assessed using Pearson's correlation. All statistical analyses were performed using SPSS v12.0 (SPSS, Inc., Chicago, IL, USA). $\mathrm{P}<0.05$ was considered to indicate a statistically significant difference.

\section{Results}

mRNA expression of GR isoforms in the PBMCs. The mRNA expression of the GR $\alpha$ and GR $\beta$ transcripts in the PBMCs of 29 CHB patients and 43 healthy controls were analyzed by RT-qPCR. The RT-PCR products of GR $\alpha$ were detected in the PBMCs of all patients and healthy controls, whereas the GR $\beta$-specific products were only found in certain samples. Of the subjects tested, GR $\beta$ mRNA was detected in the RNA from the PBMCs of 27 CHB patients (93.1\%) and 37 healthy controls $(86.0 \%)$. The incidence of GR $\beta$ expression in patients with CHB was similar to that in the healthy controls $(\mathrm{P}>0.05)$.

Quantitative analysis of the mRNA expression of GR isoforms. The mean expression levels of GR $\alpha$ were significantly different between the CHB patients and healthy controls $(\mathrm{P}<0.001)$ and were significantly lower in the CHB patients $(60.51 \pm 23.73)$ compared with those in the healthy controls $(100.00 \pm 40.75$; Table II). However, no significant differences were observed in the mRNA expression levels of GR $\beta$ between the CHB patients and healthy controls $(0.11 \pm 0.08$, vs. $0.17 \pm 0.13 ; \mathrm{P}=0.061)$. No significant correlation was observed in the RNA levels between the two splice variants in healthy controls ( $\mathrm{P}>0.05$; Fig. 1A). However, a significant positive correlation was observed between the GR $\alpha$ levels and the expression of GR $\beta$ in the PBMCs of patients with $\mathrm{CHB}(\mathrm{r}=0.419 ; \mathrm{P}<0.05$; Fig. 1B).
Table II. mRNA levels of GR $\alpha$ and GR $\beta$ in the PBMCs of healthy controls and CHB patients.

\begin{tabular}{lccr}
\hline mRNA & $\begin{array}{c}\text { Controls } \\
(\mathrm{n}=43)\end{array}$ & $\begin{array}{c}\text { CHB patients } \\
(\mathrm{n}=29)\end{array}$ & P-value \\
\hline GR $\alpha$ & $100.00 \pm 40.75$ & $60.51 \pm 23.73$ & $<0.001$ \\
GR $\beta$ & $0.17 \pm 0.13$ & $0.11 \pm 0.08$ & 0.061 \\
\hline
\end{tabular}

All mRNA levels were determined as a percentage of the mRNA levels of GR $\alpha$ in the PBMCs of healthy controls. Data are expressed as the mean \pm standard deviation. GR $\beta$ mRNA was undetected in the PBMCs of 6 healthy controls and $2 \mathrm{CHB}$ patients. GR, glucocorticoid receptor; $\mathrm{PMBC}$, peripheral blood mononuclear cell; $\mathrm{CHB}$, chronic hepatitis $\mathrm{B}$.
A

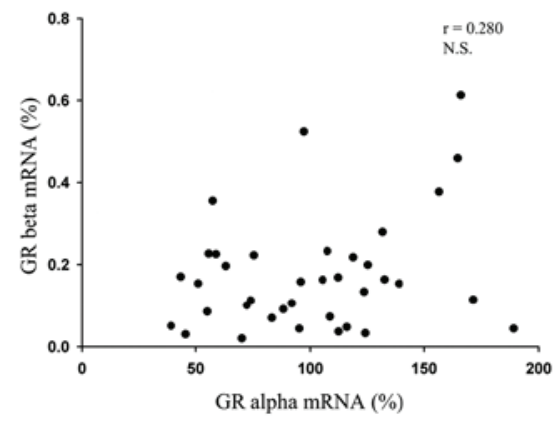

B

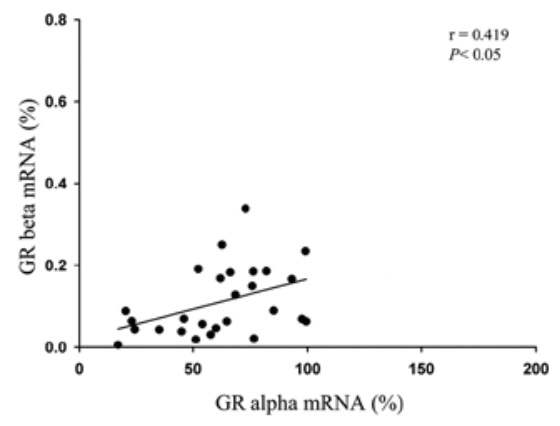

Figure 1. Correlation between the mRNA expression levels of GR $\alpha$ and GR $\beta$ in the peripheral blood mononuclear cells of (A) healthy controls and (B) chronic hepatitis B patients. All values are expressed as percentages relative to the mRNA levels of GR $\alpha$ in the healthy controls. No significant correlation was detected between mRNA expression levels of GR $\alpha$ and GR $\beta$ in healthy controls $(r=0.280 ; \mathrm{P}>0.05)$. However, a significant positive correlation was observed between mRNA expression levels of GR $\alpha$ and GR $\beta$ in patients with chronic hepatitis B $(r=0.419 ; \mathrm{P}<0.05)$. GR, glucocorticoid receptor; N.S., not significant.

Association between the mRNA expression levels of the GR isoforms and serum HBV markers. Compared with the healthy controls, lower mRNA levels of GR were observed in the CHB patients, who were further divided into subgroups according to their serum HBV marker status. The PBMC expression of GR $\alpha$ was significantly reduced in the HBeAg-positive patients $(n=13)$ and $\mathrm{HBeAg}$-negative patients $(\mathrm{n}=16)$ compared with those in the healthy controls $(\mathrm{P}<0.05$; Fig. $2 \mathrm{~A})$. Regarding the pre- $\mathrm{S} 1 \mathrm{Ag}$ status, however, only HBV pre-S1Ag-negative patients $(n=17)$ exhibited a significant decrease in GR $\alpha$ mRNA relative to the healthy controls ( $\mathrm{P}<0.05$; Fig. 2B). The GR $\beta$ mRNA values in the PBMCs were not associated with the serum HBV marker status of the patients and no significant differences were observed in 

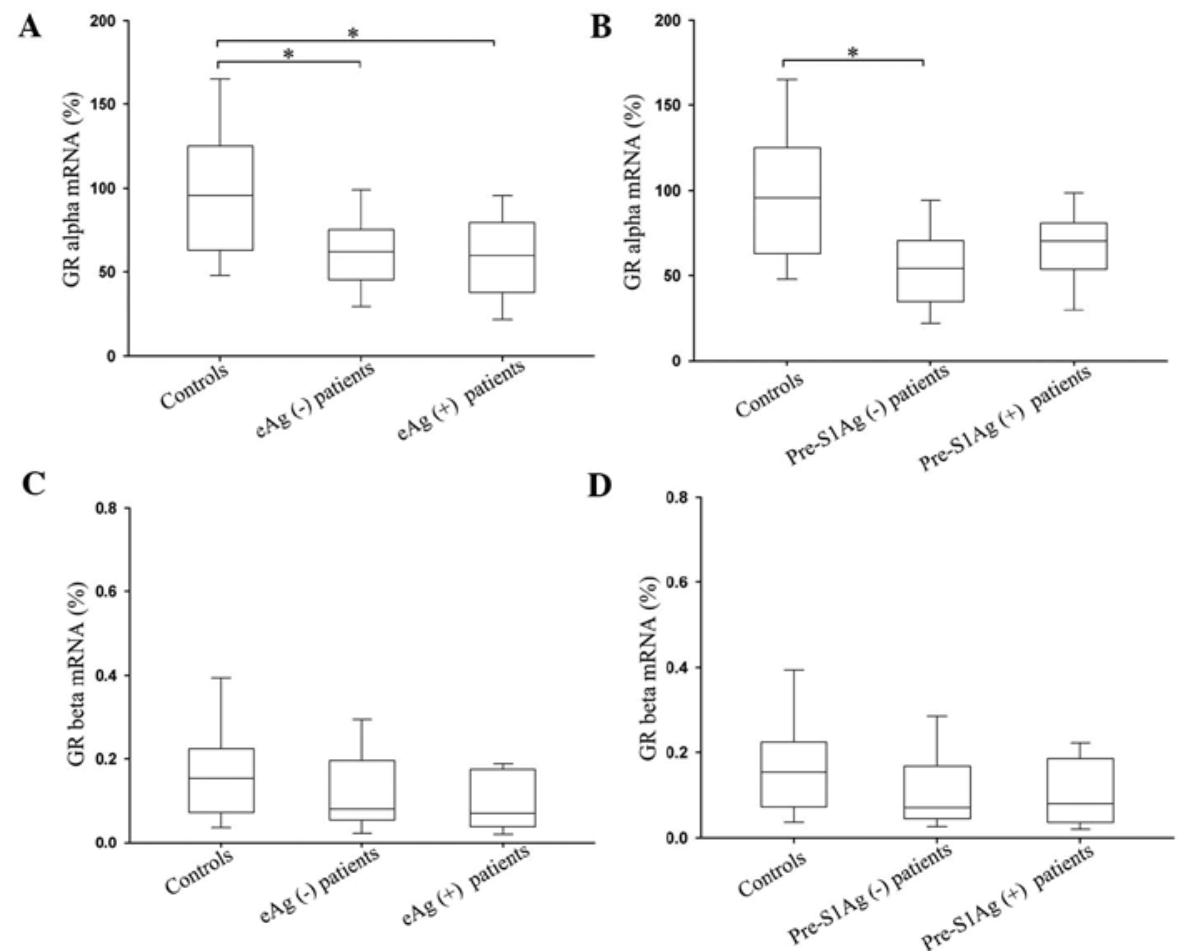

Figure 2. mRNA expression levels of (A and B) GR $\alpha$ and (C and D) GR $\beta$ in the peripheral blood mononuclear cells of chronic hepatitis B patients (stratified according to $\mathrm{HBeAg}$ and pre-S1 Ag status) and healthy controls. Boxes represent the interquartile range, solid lines in the boxes represent the medians and bars represent the minimum and maximum observations. Compared with the healthy control, significantly reduced expression of GR $\alpha$ mRA was observed in the HBeAg-positive, HBeAg-negative and pre-S1 Ag-negative patients. " $\mathrm{P}<0.05$. GR, glucocorticoid receptor; HBeAG, hepatitis B e antigen.

A

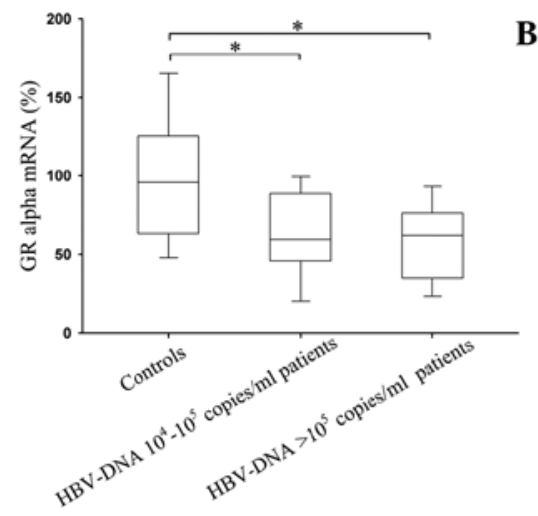

B

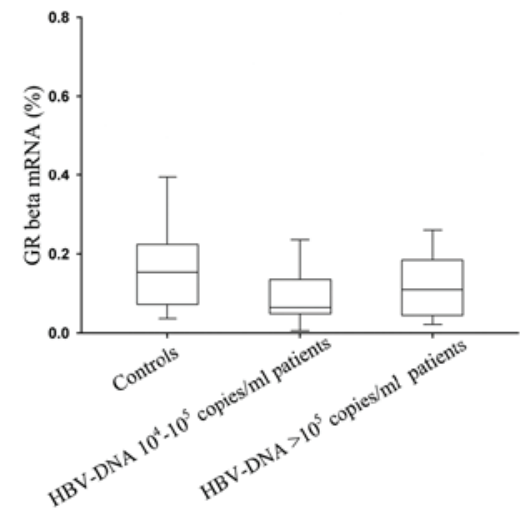

Figure 3. mRNA expression levels of (A) GR $\alpha$ and (B) GR $\beta$ in the peripheral blood mononuclear cells of chronic hepatitis B patients, stratified according to serum HBV viral load status. The boxes represent the interquartile range, the solid lines in the boxes represent the medians and the bars represent the range. Compared with the healthy control, significantly reduced expression of GR $\alpha$ mRNA was observed in patients with serum HBV viral loads of $10^{4}-10^{5}$ copies $/ \mathrm{ml}^{2}$ and $>10^{5}$ copies $/ \mathrm{ml}$. ${ }^{*} \mathrm{P}<0.05$. GR, glucocorticoid receptor; HBV, hepatitis B virus.

the expression of GR $\beta$ between the patient subgroups and the healthy controls ( $\mathrm{P}>0.05$; Fig. $2 \mathrm{C}$ and $\mathrm{D})$.

Association between the mRNA expression levels of the GR isoforms and $H B V$ viral loads. The CHB patients were divided into two sub-groups according to their levels of serum HBV DNA of $1 \times 10^{4}-10^{5}$ copies $/ \mathrm{ml}(\mathrm{n}=10)$ and $>1 \times 10^{5}$ copies $/ \mathrm{ml}$ $(\mathrm{n}=19)$. Compared with the healthy controls, the mRNA expression of GR $\alpha$ was significantly decreased in the patients of the two subgroups $(\mathrm{P}<0.05$; Fig. 3A). However, no significant difference was observed in the mRNA expression of GR $\beta$ between the controls and either the $1 \times 10^{4}-10^{5}$ copies $/ \mathrm{ml}$ or the $>1 \times 10^{5}$ copies/ml subgroup ( $\mathrm{P}>0.05$; Fig. 3B). In terms of the association between serum HBV viral load and the GR mRNA levels, no correlation was observed in the HBV DNA-positive patients, as demonstrated by the HBV viral load and the mRNA expression levels in the CHB patients (Fig. 4A and B).

\section{Discussion}

GR $\alpha$ and GR $\beta$ mRNA are generated by alternative splicing of common GR gene transcripts, which contain exon 9a and 9b gene transcripts. GR $\alpha$ is a ligand-activated transcription factor, whereas GR $\beta$ may be an endogenous inhibitor of 
A

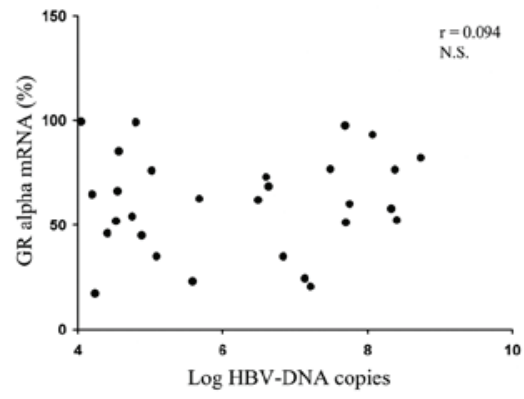

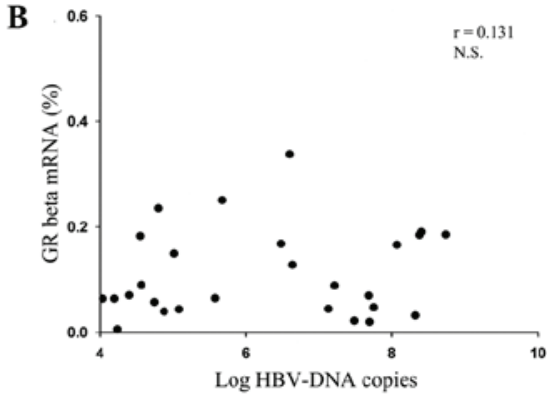

Figure 4. Association between the serum HBV viral load and the mRNA expression levels of (A) GR $\alpha$ and (B) GR $\beta$ in the peripheral blood mononuclear cells of chronic hepatitis B patients. The GR $\alpha$ and GR $\beta$ values are expressed as percentages relative to the mRNA expression levels of GR $\alpha$ in the healthy controls. HBV, hepatitis B virus; GR, glucocorticoid receptor; N.S., not significant.

glucocorticoid action and transcriptionally inactive (16). In the present study, the mRNA expression levels of GR $\alpha$ and GR $\beta$ in the PBMCs of CHB patients and healthy individuals were quantified using RT-PCR and the association between the mRNA expression of the GR isoforms and HBV serological and virological markers was examined.

A previous study by Rai et al (17) indicated that GR $\alpha$ mRNA exists in the PBMCs of all autoimmune hepatitis (AIH) patients, chronic viral hepatitis $(\mathrm{CVH})$ patients and healthy volunteers and that the incidence of GR $\beta$ mRNA in AIH patients $(57.6 \%)$ is significantly higher compared with that in patients with $\mathrm{CVH}(28.6 \%)$ and healthy volunteers $(20.0 \%)$. In the present study, GR $\alpha$ mRNA was also present in the PMBCs of all subjects, whereas GR $\beta$ mRNA was detected in the PBMCs of $93.1 \%$ CHB patients and $86.0 \%$ healthy controls. In addition, the expression of GR $\beta$ in the patients with $\mathrm{CHB}$ was not significantly different from that in the healthy volunteers $(\mathrm{P}>0.05)$ and the mRNA expression of GR $\beta$ was markedly higher. The discrepancy between the incidences of GR $\beta$ may result from differences in the population studied and the sensitivity of the methods used.

The mRNA expression of GR $\beta$ has been demonstrated in various human tissues by RT-PCR. Compared with GR $\alpha$, the levels of GR $\beta$ were observed to be relatively low and considered to be $0.2-0.3 \%$ of GR $\alpha$ mRNA levels (10). In the present study, the mRNA levels of GR $\beta$ were $0.17 \pm 0.13 \%$ in the healthy controls and $0.11 \pm 0.08 \%$ in the $\mathrm{CHB}$ patients relative to those of GR $\alpha$.

Gao et al (18) investigated the expression of GR in $\mathrm{T}$ lymphocytes in patients with acute onset of chronic hepatitis $\mathrm{B}$ liver failure and $\mathrm{CHB}$. The results revealed that the mRNA expression of GR $\alpha$ in $\mathrm{CHB}$ patients was significantly decreased compared with that in healthy controls; however, the difference in the mRNA expression of GR $\beta$ between CHB patients and healthy controls was not significant. The findings of the present study were consistent with this, as, compared with those of the healthy controls, the mRNA levels of GR $\alpha$ in the $\mathrm{CHB}$ patients was significantly lower $(60.51 \pm 23.73$, vs. $100.00 \pm 40.75 ; \mathrm{P}<0.001)$. The mRNA expression of GR $\beta$ in the $\mathrm{CHB}$ patients also declined; however, the difference in these values was not significant between the two groups $(0.11 \pm 0.08$, vs. $0.17 \pm 0.13 ; \mathrm{P}=0.061)$. In a previous study, a significant correlation was identified between the mRNA expression levels of GR $\alpha$ and GR $\beta$ in the PBMCs of healthy controls and patients with Cushing's syndrome (19). In the present study, the GR $\alpha$ levels were only significantly positively correlated with the expression of GR $\beta$ in the PBMCs of CHB patients $(r=0.419$; $\mathrm{P}<0.05$; Fig. 1B), while no such correlation was observed in the PBMCs of the healthy controls.

At present, the mechanisms underlying the decreased mRNA expression of GR in the PBMCs of CHB patients remain to be elucidated. A possible mechanism underlying the downregulation of GR mRNA may involve the inability of PBMCs to produce peptides and protein following HBV infection. HBV is not strictly hepatotropic, early observations have demonstrated that this virus can infect PBMCs and viral DNA is detectable in the PBMCs of the majority of CHB patients (20). The PBMC cell compartment represents an extra-hepatic viral reservoir, not only during infection, but for an extended time following resolution of acute hepatitis B (21). Previous studies have demonstrated a dysregulation of pro- and anti-inflammatory cytokines in $\mathrm{CHB}$ patients and elevated levels of proinflammatory cytokines may inhibit the expression and function of GR, weakening its anti-inflammatory and immunoregulatory effects during a systemic inflammatory response $(22,23)$. Furthermore, the mRNA levels of GR $\beta$ were low compared with total GR levels and their effect on the action of GR $\alpha$ is limited, suggesting that concomitant downregulation in the mRNA expression levels of GR $\alpha$ and GR $\beta$ in the PBMCs of CHB patients may result in attenuation, rather than enhancement, of glucocorticoid efficacy (24).

The relatively low mRNA expression levels of GR $\beta$ compared with those of GR $\alpha$ may contribute to the lack of significance between differences in the mRNA expression of GR $\beta$ in CHB patients and healthy controls. Exogenously administered glucocorticoid may downregulate mRNA levels of GR $(24,25)$. However, in the present study, this possibility can be excluded as the CHB patients had not received glucocorticoid treatment for $>$ six months prior to blood sampling.

The HBV genome contains a specific DNA binding site for the GR localized at HBV map positions 341-370, which serves as a signal for augmenting the glucocorticoid-dependent activity of the HBV enhancer (12). In vivo, glucocorticoid therapy in $\mathrm{CHB}$ patients may result in activation of latent infection, increasing levels of HBV markers and increasing the severity of liver disease, implying that glucocorticoids are involved in HBV replication and gene expression (26). In vitro, glucocorticoid can increase the production of $\mathrm{HBsAg}$, HBeAg and viral RNAs, mediated through specific GRs, in HBV-transfected human hepatoma cells (11). In addition, 
a previous study reported that serum levels of the endogenous glucocorticoid cortisol were marginally higher in $\mathrm{CHB}$ patients compared with those in healthy controls, although the difference was not significant (18).

The present study further examined the association between the mRNA expression of the GR isoforms and HBV serum markers and viral status in CHB patients. To the best of our knowledge, there is little reference to this area in previous studies. Compared with the healthy controls, significant differences were observed in the mRNA expression levels of GR $\alpha$ in the HBeAg-positive and HBV DNA-positive CHB patients $(\mathrm{P}<0.05)$. The mechanisms underlying these findings remain to be elucidated, although it can be hypothesized that the endogenous glucocorticoid stimulated the production of HBeAg and HBV DNA through the mechanisms mentioned above and that, when the concentrations of HBV protein antigens and HBV DNA reach a certain limit, feedback mechanisms downregulate the production of GR $\alpha$. The concentrations of HBV antigen and HBV viral load were particularly high in $\mathrm{CHB}$ patients.

Significant differences were also observed in the mRNA expression of GR $\alpha$ in HBeAg-negative and pre-S1Ag-negative patients with $\mathrm{CHB}$ compared with those in the healthy controls. These CHB patients also had high concentrations of other HBV serological and virological markers, including $\mathrm{HBsAg}$ and $\mathrm{HBV}$ DNA, which were likely to have induced feedback mechanisms that downregulate the expression of GR $\alpha$. The details of these feedback mechanisms, however, remain to be elucidated.

In conclusion, the present study demonstrated that the mRNA expression profile of GR $\alpha$ was different between $\mathrm{CHB}$ patients and healthy controls. Although the expression of GR $\alpha$ in the CHB patient subgroups was found to significantly decrease compared with that in the healthy controls, the HBV serological and virological marker status was not associated with the mRNA levels of the GR isoforms in the CHB patients.

\section{Acknowledgements}

This study was financially supported by the Hubei Provincial Science \& Technology Department Research Program of China (no. 2007AA301C54).

\section{References}

1. Custer B, Sullivan SD, Hazlet TK, et al: Global epidemiology of hepatitis B virus. J Clin Gastroenterol 38: S158-S168, 2004.

2. Wright TL and Lau JY: Clinical aspects of hepatitis B virus infection. Lancet 342: 1340-1344, 1993.

3. Ganem D and Prince AM: Hepatitis B virus infection - natural history and clinical consequences. N Engl J Med 350: 1118-1129, 2004.

4. Pan CQ and Zhang JX: Natural history and clinical consequences of hepatitis B virus infection. Int J Med Sci 2: 36-40, 2005.

5. Belle A, Bronowicki JP and Peyrin-Biroulet L: Reactivation of viral hepatitis in immunosuppressed patients: an ounce of prevention is worth a pound of cure. Gastroenterology 140: 360-362, 2011.
6. Kim MK, Ahn JH, Kim SB, et al: Hepatitis B reactivation during adjuvant anthracycline-based chemotherapy in patients with breast cancer: a single institution's experience. Korean J Intern Med 22: 237-243, 2007.

7. Lee SD, Tong MJ, Wu JC, et al: A randomised double-blind placebo-controlled trial of prednisolone therapy in $\mathrm{HBeAg}$ and HBV DNA positive Chinese patients with chronic active hepatitis B. J Hepatol 12: 246-250, 1991.

8. Hollenberg SM, Weinberger C, Ong ES, et al: Primary structure and expression of a functional human glucocorticoid receptor cDNA. Nature 318: 635-641, 1985.

9. Bamberger CM, Schulte HM and Chrousos GP: Molecular determinants of glucocorticoid receptor function and tissue sensitivity to glucocorticoids. Endocr Rev 17: 245-261, 1996.

10. Oakley RH, Sar M and Cidlowski JA: The human glucocorticoid receptor beta isoform. Expression, biochemical properties, and putative function. J Biol Chem 271: 9550-9559, 1996.

11. Chou CK, Wang LH, Lin HM and Chi CW: Glucocorticoid stimulates hepatitis B viral gene expression in cultured human hepatoma cells. Hepatology 16: 13-18, 1992.

12. Tur-Kaspa R, Shaul Y, Moore DD, et al: The glucocorticoid receptor recognizes a specific nucleotide sequence in hepatitis B virus DNA causing increased activity of the HBV enhancer. Virology 167: 630-633, 1988.

13. Lok AS and McMahon BJ: Chronic hepatitis B. Hepatology 45: 507-539, 2007.

14. Boullu-Ciocca S, Paulmyer-Lacroix O, Fina F, et al: Expression of the mRNAs coding for the glucocorticoid receptor isoforms in obesity. Obes Res 11: 925-929, 2003.

15. Hettinger AM, Allen MR, Zhang BR, et al: Presence of the acute phase protein, bikunin, in the endometrium of gilts during estrous cycle and early pregnancy. Biol Reprod 65: 507-513, 2001.

16. Okano M: Mechanisms and clinical implications of glucocorticosteroids in the treatment of allergic rhinitis. Clin Exp Immunol 158: 164-173, 2009.

17. Rai T, Ohira H, Tojo J, et al: Expression of human glucocorticoid receptor in lymphocytes of patients with autoimmune hepatitis. Hepatol Res 29: 148-152, 2004.

18. Gao L, Wang JF, Xiang M, et al: Expression of human glucocorticoid receptor in T lymphocytes in acute-on-chronic hepatitis B liver failure. Dig Dis Sci 56: 2605-2612, 2011.

19. Hagendorf A, Koper JW, de Jong FH, et al: Expression of the human glucocorticoid receptor splice variants alpha, beta, and $\mathrm{P}$ in peripheral blood mononuclear leukocytes in healthy controls and in patients with hyper- and hypocortisolism. J Clin Endocrinol Metab 90: 6237-6243, 2005.

20. Pontisso P, Vidalino L, Quarta S and Gatta A: Biological and clinical implications of HBV infection in peripheral blood mononuclear cells. Autoimmun Rev 8: 13-17, 2008.

21. Michalak TI, Pasquinelli C, Guilhot S and Chisari FV: Hepatitis B virus persistence after recovery from acute viral hepatitis. J Clin Invest 93: 230-239, 1994.

22. Gustot T, Durand F, Lebrec D, Vincent JL and Moreau R: Severe sepsis in cirrhosis. Hepatology 50: 2022-2033, 2009.

23. Schlaak JF, Tully G, Löhr HF, Gerken G and Meyer zum Büschenfelde KH: HBV-specific immune defect in chronic hepatitis $\mathrm{B}(\mathrm{CHB})$ is correlated with a dysregulation of pro-and anti-inflammatory cytokines. Clin Exp Immunol 115: 508-514, 1999.

24. Hori T, Watanabe K, Miyaoka M, et al: Expression of mRNA for glucocorticoid receptors in peripheral blood mononuclear cells of patients with Crohn's disease. J Gastroenterol Hepatol 17: 1070-1077, 2002.

25. Peeters RP, Hagendorf A, Vanhorebeek I, et al: Tissue mRNA expression of the glucocorticoid receptor and its splice variants in fatal critical illness. Clin Endocrinol (Oxf) 71: 145-153, 2009.

26. Yang $\mathrm{CH}, \mathrm{Wu} \mathrm{TS}$ and Chiu $\mathrm{CT}$ : Chronic hepatitis B reactivation: a word of caution regarding the use of systemic glucocorticosteroid therapy. Br J Dermatol 157: 587-590, 2007. 